\title{
Psychological and Social Borders: Regulating Relationships
}

\author{
Giuseppina Marsico (University of Salerno, Italy) \\ Achille Varzi (Columbia University, USA)
}

[Final version published in J. Valsiner, G. Marsico, N. Chaudhary, T. Sato, and V. Dazzani (eds.), Psychology as a Science of Human Being, Berlin, Springer-Verlag, 2015, pp. 327-336]

\begin{abstract}
Psychological phenomena take place at the border between person and environment. Indeed, psychology as a whole may be seen as a science of human liminal constructions, a science concerned with the dynamic relationships that exist between people and what surrounds them and with the constant border crossing that defines the arena within which all human development takes place. From this perspective, the central question becomes: how do humans deal with such transitions throughout the course of their lives? Cultural psychology offers a way of addressing, theoretically and empirically, the epistemological and social dimensions of this question. In addition, we argue that mereotopology - the theory of the relations of part to whole and of part to part within a whole-provides a conceptual framework of enormous potential for appreciating its unexplored ontological underpinnings, thus contributing to the foundations of psychology as a developmental science of the inherent uncertainty that accompanies all individual and social becoming.
\end{abstract}

Psychological phenomena take place at the border between person and environment. Indeed, psychology as a whole may be seen as a science of human liminal constructions, a science concerned with the dynamic relationships that exist between people and what surrounds them. The person-context relationship is, therefore, a central topic in a number of different domains of psychological research, taking on special importance when applied to the study of human development (Kindermann \& Valsiner, 1995).

Lev Vygotsky's early attempt to deal with "the problem of the environment" in child development offers a good illustration of the double-barrelled nature of this perspective. According to Vygotsky (1994), the child's development entails, on the one hand, a progressive widening of the environment, from the circumscribed space related to his or her existence immediately after birth to the wider portions that gradually open up as the child starts walking: the house, the street, the neighbourhood, etc. And even further:

his environment changes according to the different kinds of environment each stage of his education provides: during his nursery school age, the nursery school; during 
his immediate pre-school years, the kindergarten; and during the school age, the school. Every age presents the child with an environment which has been organized in a special way, so that the environment, in the purely external sense of the word, keeps changing as the child passes on from one age to another. (Vygotsky 1994, p. 339)

On the other hand, even when the environment may seem to remain unchanged, the simple fact that the child changes in the process of his personal development introduces significant modifications in his relation with specific external factors:

the same environmental factors which may have one meaning and play a certain role during a given age, two years on begin to have a different meaning and to play a different role because the child has changed. (Ibid.)

It thus appears that, along their developmental trajectory, human beings are engaged in an uninterrupted crossing of borders in their life space (Marsico, 2013; Marsico et al., 2013). By crossing borders, they automatically create new ones. How do humans deal with such qualitative transitions throughout the course of their lives?

\section{Development as a qualitative structural transformation of borders}

The process of moving ahead in life, with its constant border crossing, defines the arena within which all human development takes place. Such a development is, in essence, an unfinished and open-ended process, grounded on the epistemology of becoming and bounded by the irreversibility of time (Valsiner \& van der Veer, 2014; Marsico, 2015). Emergence of new qualitative levels of organization is thus the core issue in human development, which involves feed-forward processes that guide each living organism to face the uncertainty of future states in its relations with the environment (Valsiner, 2008). This way to conceptualize the development creates a difficulty for scientists who are in search of order and stability, which are antithetical to any developmental process based on discontinuity and ruptures of the previous order. The theoretical challenge is to capture both the certain and the uncertain aspects of the developing system as well as the open-endedness of the future in connection with the uniqueness of the past-to-present trajectory. The timeline of this trajectory in an irreversible time is the axiomatic core of any developmental perspective needed to recognize that an event occurring at time T1 is typically similar, but never identical, to any subsequent event at time T2 (Sovran, 1992). The irreversibility of time entails the continuity of change from an infinite past towards an infinite future. 
Thus, development deals with the process of becoming, not with states of being. It requires that we look at what is possible in the future, beyond what is actually present. As Baldwin pointed out in his "genetic logic",

that series of events is truly genetic which cannot be constructed before it has happened, and which cannot be exhausted backwards, after it has happened. (Baldwin 1906, p. 21)

It follows that the study of development needs to be grounded on the unfolding of novel processes, rather than on their prediction or on retrospective explanation. The phenomena of emergence, becoming, and transformation are, therefore, the real objects of investigation in developmental science. (Valsiner \& van der Veer, 2014)

The structural transformation of a person in irreversible time and within contexts is well represented even in the earliest documented occurrence of Vygotsky's notion of Zone of Proximal Development (ZPD).

Investigations led paedologists to the idea that one should determine at least a double level of child development, namely: first, the level of actual development of the child, i.e., that which has already matured to the present day; and, secondly, the zone of his nearest development, i.e., those processes in the further development of these same functions which, as they are not mature today, still are on their way already, are already growing through, and already tomorrow will bear fruit; already tomorrow transfer to the level of actual development. (Vygotsky, 1933/1935, p. 120)

Here the conceptual value of ZPD as a border is evident. The Zone of Proximal Development is focused on the dynamic process of emergence and constitutes a fluid border between the already-developed and the not-yet-developed functions. A growing person constantly moves beyond what is already acquired towards what is not yet achieved (Boesch, 1991). The space in between, as described in ZPD, provides the feed-forward loop between organism and environment in the process of qualitative transformation of the psychological structures trough the myriad of borders that define them (Marsico, 2011).

We may say that the Zone of Proximal Development is grounded on the partwhole relation. It has a holistic character that comprehends the unity of the parts in a whole, comprising itself and the neighbouring zones (the Zone of Actual Development and the Zone of Insurmountable Difficulties; Zaretskii, 2009). It belongs to the person who has developed up to this moment, but it is oriented towards exploring the beyond-area (Boesch,1991). It is, again the border between what has already emerged and what has not yet happened but might happen. 


\section{Parts and Wholes}

The part-whole relation has been the subject of philosophical inquiry since antiquity, not least because all reality, including ourselves, appears to be hierarchically structured in terms of entities of greater and greater complexity (Varzi, 2015). It has, of course, also been central to psychological inquiry, most notably Gestalt psychology (Smith, 1988). As an autonomous field of research, however, the formal study of the part-whole relation is a relatively recent development, leading to a theoretical framework that has come to be known as "mereotopology" (Smith, 1996; Varzi, 1996). Mereotopology deals both with the relations of part to whole and with the relations of part to part within a whole. As such, the framework embodies two different but interconnected components: a mereological component, which focuses on the relational concept of parthood, and a topological component, which is concerned with the relation of connection and, derivatively, the monadic property of wholeness. (Smith, 1997; Casati \& Varzi, 1999; Smith and Varzi, 2000; Varzi, 1997, 1998).

There is no general agreement on exactly what principles govern these two components and their mutual interplay (Varzi, 1997; 1998; 2007; Cohn \& Varzi, 2003). For our purposes, suffice it to say that parthood is typically viewed as forming a partial order, i.e., a relation that is reflexive (everything is part of itself), antisymmetric (no two things are part of each other), and transitive (any part of a part of a thing is itself part of that thing), with the additional property that no composite thing can have a single proper part. Similarly, the connection relation is inherently reflexive (everything is connected to itself), symmetric (if a thing is connected to a second thing, the second is connected to the first), and monotonic with respect to parthood (everything is connected to anything to which its parts are connected).

Other principles are more controversial. For instance, there is disagreement on whether parthood is an extensional relation (to the effect that composite things with the same proper parts are identical), or on whether composition is unrestricted (in the sense that any number of things form a whole, regardless of their homogeneity or causal unity). Still, the framework is at least precise enough to allow such questions to be raised and formulated in precise terms. More importantly, it provides the basis for addressing two additional questions that bear directly on our topic: first, how does the part-whole relation behave vis à vis such dynamic factors as the relative movement of parts or the dependence of a whole from the parts that compose it? Second, what does mereotopology tells us about the dynamics of border contact, and more generally about the relationship between a border and the thing it bounds? 
The first question is especially important if we are interested, not only in the way in which wholes are organized, but in how they evolve through time, including the loss of old parts and the acquisition of new ones. Valsiner's notion of inclusive separation (Valsiner 1987) captures some basic structural and functional relationships between parts and wholes that are sensitive to the idea that mereotopological development is, ultimately, a product of the continuous trade-off between what is already acquired and what is not yet achieved. There remains to be seen how such structural and functional relationships can be modelled in terms of the fundamental conceptual primitives of mereotopology, i.e., parthood and connection, so as to see the effects of inclusive separation on the other principles mentioned above.

As for the second question, mereotopology brings out the seemingly paradoxical nature of borders as the loci of contact between the inside and the outside of any given whole, beginning with ourselves (Varzi, 1997). A border separates the two sides; but the sides are also said to be continuous with each other. If they were not continuous, something would lie between them, so the border of one (the inside) would not be the border of the other (the outside). Yet, if they are continuous, the question arises: which side owns the border, mereologically speaking? The border cannot be part of both, for otherwise the inside and the outside would overlap, which is impossible. And it cannot be part of neither, for otherwise the inside and the outside would not be truly in contact owing to the density of the continuum. Yet any other choice would seem to amount to a peculiar privileging of one side over the other, a result that already Brentano (1906) stigmatized as "monstrous" and Chisholm as logically incoherent:

If the continuous object is cut in half, then does the one boundary become two boundaries? [...] But how can one thing - even if it is only a boundary-become two things? (Chisholm 1984, p. 88)

It is tempting to think that figure/ground considerations should be invoked here, based on the principle that the border is always part of the whole, hence of the figure inside (Jackendoff, 1987, Appendix B); the outside - the backgroundis topologically "open". Yet what is figure and what is ground when it comes to two adjacent halves of a single integral whole? What happens when we take the two halves apart? Indeed, it would be natural to suppose that all entities of the same sort be treated alike, for instance, that all material bodies be construed as figure-like entities, each possessing its own border. But then, how could any two of them ever come into contact, short of penetrability? (Kline \& Matheson, 1987) 
This puzzle is, really, a sign of the deeply ambivalent, highly fluid nature of borders. Ultimately, it bears witness to the intuitive limits of mereotopology as a formal theory of border phenomena, and many philosophers and logicians are led to conclude that borders are not genuine denizens of reality: they are merely mental constructions, mathematical abstractions, façons de parler (Gotts et al., 1996). Yet this is hardly a solution if we are interested in the mechanisms of constant border crossing that are characteristic of human evolution. The struggle between inside and outside that takes place at the border, in the spatial as well as in the temporal dimension, is precisely what affects our psychology most deeply. And the science of psychology is itself constantly striving with ambivalence and indeterminacy, both at the level of individual development and in relation to all sorts of phenomena evolving in the socio-cultural sphere (Abbey, 2012). A mereotopological characterization of the puzzle, even without an obvious solution, is part of what it takes to come to terms with such pervasive ambivalence and indeterminacy.

\section{Borders and causal explanation: the catalytic process}

The ambivalent topological nature of borders - which simultaneously "separate" and "connect" - blends naturally with the mereological fluidity of the relations between the different internal parts of a dynamic system. Here, too, we need to augment the abstract mereotopological stance by looking at concrete border conditions in terms of their open-ended plasticity. What counts as a border now may and typically will no longer count as a border at a later stage, just as what counts as a part may vary across time. Things grow, shrink, come apart, merge with other things, constantly acquiring new parts and losing old ones. Following Neuman (2003), borders may in this sense be construed as involving an "oscillatory process" between the inside and the outside - between the bounded entity and its environment - whose primal features cannot even be defined before the relevant interactions take place.

A way to foster this intuition involves causal considerations: what kind of causal explanation would allow us to vindicate the dynamicity of such oscillatory processes? The causal unity of the whole is often invoked in accounting for a thing's interactions with the environment, and when it comes to such things as living organisms, biological factors may well play a central function in this regard (Wilson, 1999). Gestalt theory also emphasizes causal unity as a primary factor in accounting for the integrity of a whole, both synchronically and diachronically (Bozzi, 1969). From a cultural psychological perspective, however, it seems more 
appropriate to speak of semiotic catalysis (Valsiner, 2000; 2014), where "catalysis" refers to the contextual conditions that need to be present for a particular causal linkage to occur. Semiotic catalysis spotlights the systemic, transformative, developmental nature of the relevant causal processes as well as the heterogeneous variety of outcomes that result (Cabell \& Valsiner, 2013). It emphasizes the systemic relations between parts and borders, explicating how such relations determine a variety of conditions that appear to be necessary, but not in themselves sufficient, for qualitative transformations that are psychologically salient. And since catalytic causation is non-linear, reference to this concept may prove decisive in the psychological study of complex systems and of the mutual simultaneous, "oscillatory" causal relationships that obtain between opposite and ambivalent elements.

By activating a phenomenal field, catalysis also makes it possible to account for the dynamic construction, regulation, and negotiation of borders. In particular, contextualizing catalysis plays up a bidirectional mechanism: by enabling the production of new meanings, feelings, and emotions, catalysis contributes to creating new territories - with their specific borders - in human geography. At the same time, as soon as we create them, borders redefine the entire system and the quality of the relations among parts and whole, acting as semiotic catalysers and producing novel patterns of thought and behaviour. This is evident in the geo-political world, where the drawing of borders typically results in people on the opposite sides speaking different languages, relying on different authorities, and struggling to solve their problems and to improve the quality of their common life. Such is the magic of boundary lines: they are thin, yet powerful; they separate, and thereby unite; they are invisible, yet a lot depends on them, including one's sense of belongingness to a country, a people, a place. The same is true of the borders that define our individuality and that constrain our development qua human beings: we identify and re-identify ourselves as complex systems separated from, though connected with, whatever else belongs to our environment. The causal history of our borders is the history of our lives.

\section{Concluding remarks}

Developmental psychology calls for a general theory of becoming that fully acknowledges the centrality of liminal constructions in human life and the oscillatory nature of the borders that keep us apart from our environments. This, in turn, calls for an ontogenetic perspective that takes at face value the open-ended plasticity that is characteristic of all dynamic systems, and of human beings in particular, as they evolve irreversibly through time. The epistemological and social dimen- 
sions of this task have become of central importance in cultural psychology, where individual and societal borders are seen as semiotic catalysers of the continuous trade-off between what is already acquired and what is not yet achieved. In addition, mereotopology - the formal theory of the relations of part to whole and of part to part within a whole - provides a conceptual framework of enormous potential for appreciating the logial and ontological dimensions of the task at issue. The conceptual interplay between all these dimensions, and between the theoretical tools needed to investigate them, is still relatively unexplored. When better understood and fully developed, it may constitute a powerful contribution to the foundations of psychology as a developmental science of the inherent qualitative transformations that accompany all individual and social becoming.

\section{References}

Abbey, E. (2012). Ambivalence and its transformation. In J. Valsiner (Eds.), Oxford handbook of culture and psychology (pp. 989-997). New York: Oxford University Press.

Baldwin, J.M. (1906). Thought and things: A study of the development and meaning of thought, or genetic logic. Vol. 1. Functional logic, or genetic theory of knowledge. London: Swan Sonnenschein \& Co.

Boesch, E. (1991). Symbolic action theory and cultural psychology. Berlin: SpringerVerlag.

Bozzi, P. (1969). Unità, identità, causalità. Bologna: Cappelli.

Brentano, F. (1906). Nativistische, empiristische und anoetistische Theorie unserer Raumvorstellung. In his Philosophische Untersuchungen zu Raum, Zeit und Kontinuum, ed. by S. Körner \& R. M. Chisholm (pp. 164-177). Hamburg: Meiner.

Cabell, K.R. \& Valsiner J. (Eds.) (2013). The catalyzing mind. New York: SpringerVerlag.

Casati, R. \& Varzi, A.C. (1999). Parts and places: The structures of spatial representation. Cambridge, MA: MIT Press.

Chisholm, R.M. (1984). Boundaries as dependent particulars. Grazer philosophische Studien, 10: 87-95.

Cohn, A.G. \& Varzi, A.C. (2003). Mereotopological connection. Journal of Philosophical Logic, 32: 357-390.

Gotts, N., Gooday J. \& Cohn A.G. (1996). A connection-based approach to commonsense topological description and reasoning. The Monist, 79(1), 51-75.

Jackendoff, R. (1987). Consciousness and the computational Mind. Cambridge, MA: MIT Press

Leśniewski, S. (1916). Podstawy ogólnej teoryi mnogości. I, Moscow: Prace Polskiego Koła Naukowego w Moskwie, Sekcya matematyczno-przyrodnicza. 
Kindermann, T. \& Valsiner, J. (Eds.) (1995). Development of person context relations. Hillsdale, NJ: Lawrence Erlbaum Associates.

Kline, D. \& Matheson, C. A. (1987), The impossibility of collision. Philosophy, 62: 509515.

Marsico, G. (2011). The "non-cuttable" space in between: Context, boundaries and their natural fluidity, IPBS: Integrative Psychological and Behavioral Science, 45 (2), $185-193$.

Marsico, G. (2013). Moving between the social spaces: Conditions for boundaries crossing. In G. Marsico, K. Komatsu, \& A. Iannaccone (Eds.) Crossing boundaries. Intercontextual dynamics between family and school (pp. 361-374). Charlotte, NC: Information Age Publishing.

Marsico, G. (2015). Developing with time: Defining a temporal mereotopology. In L.M. Simão, D. S. Guimarães \& J. Valsiner (Eds.) Temporality: Culture in the flow of human experience. Charlotte, NC: Information Age Publishing

Marsico G., Cabell K. R., Valsiner J. \& Kharlamov N.A. (2013). Interobjectivity as a border: The fluid dynamics of "betweenness. In G. Sammut, P. Daanen, \& F. Moghaddam (Eds.) Understanding the self and others: Explorations in intersubjectivity and interobjectivity (pp. 51-65). London: Routledge.

Neuman, Y. (2003). Process and boundaries of the mind: Extending the limit line. New York: Kluwer Acadmic/Plenum Publisher.

Smith, B. (Ed.) (1988). Foundations of Gestalt theory. Munich: Philosophia Verlag.

Smith, B. (1996). Mereotopology: A theory of parts and boundaries. Data and Knowledge Engineering, 20, 287-303.

Smith, B. (1997). Boundaries: An essay in mereotopology. In L.H. Hahn (Ed.), The philosophy of Roderick Chisholm (pp. 534-561). Chicago, IL: Open Court.

Smith, B., \& Varzi, A. (2000). Fiat and bona fide boundaries. Philosophy and Phenomenological Research, 60, 401-420.

Sovran, T. (1992). Between similarity and sameness. Journal of Pragmatics, 18, 329-344.

Valsiner, J. (1987). Culture and the development of children's action. Chichester, West Sussex: Wiley.

Valsiner, J. (2000). Culture and human development: An introduction. London: Sage.

Valsiner, J. (2008). Open intransitivity cycles in development and education: Pathways to synthesis, European Journal of Psychology of Education, 23(2), 131-147.

Valsiner, J. (2014). An Invitation to cultural psychology. London: Sage.

Valsiner, J., \& van der Veer, R. (2014). Encountering the border: Vygotsky's zona blizaishego razvitya and its implications for theory of development. In A. Yasnitsky, R. van der Veer \& M. Ferrari (Eds.), The Cambridge handbook of cultural-historical psychology (pp. 148-173). Cambridge: Cambridge University Press.

Varzi, A.C. (1996). Parts, wholes, and part-whole relations: The prospects of mereotopology. Data and Knowledge Engineering, 20: 259-286.

Varzi, A.C. (1997). Boundaries, continuity, and contact. Noûs, 31, 26-58. 
Varzi, A.C. (1998). Basic problems of mereotopology. In N. Guarino (Ed.), Formal ontology in information systems (pp. 29-38). Amsterdam: IOS Press.

Varzi, A.C. (2007). Spatial reasoning and ontology: Parts, wholes, and locations. In M. Aiello , I. Pratt-Hartmann \& J. van Benthem (Eds.), Handbook of spatial logics (pp. 945-1038). Berlin: Springer-Verlag.

Varzi A.C. (2013), Boundary. In E. Zalta (Ed.), The Stanford encyclopedia of philosophy, Winter 2013 Edition.

Varzi A.C. (2015), Mereology. In E. Zalta (Ed.), The Stanford encyclopedia of philosophy, Spring 2015 Edition.

Vygotsky, L.S. (1933/1935). O pedologicheskom analize pedagogicheskogo protsessa. In L.S. Vygotsky, Umstvennoie razvitie detei v protsesse obuchenia (pp. 116-134). Moscow-Leningrad: Gosudarstvennoie Uchebno-pedagogicheskoie Izdatel'stvo.

Vygotsky, L.S. (1994), The problem of the environment. In R. van der Veer \& J. Valsiner (Eds.) The Vygotsky reader, (pp. 338-354). Oxford: Blackwell (Eng. trans. of the fourth chapter of L.S. Vygotsky, Osnovy pedologii (pp. 58-78). Leningrad: Izdanie Instituta, 1935.)

Wilson, J. (1999). Biological individuality: The identity and persistence of living entities, New York: Cambridge University Press.

Zaretskii, V.K. (2009). The zone of proximal development: What Vygotsky did not have time to write. Journal of Russian and East European Psychology, 476, 70-93 [Eng. trans. of V.K. Zaretskii. Kul'turno-istoricheskaia psikhologiia. Zona blizhaishego razvitiia - o chem ne uspel napisat' Vygotskii. Kul'turno-istoricheskaia psikhologiia, 3, 2007, 96-104] 